\title{
Integrating Intercultural Communication Competencies into Foreign Languages Learning in the Industrial Revolution Era 4.0
}

\author{
Vera Yulianti ${ }^{1}$ \\ \{vera.yulianti@uai.ac.id $\left.{ }^{1}\right\}$ \\ Universitas Al Azhar Indonesia, Komp. Masjid Agung Al Azhar, Jalan Sisingamangaraja, \\ Kebayoran Baru, Jakarta 12110, Indonesia ${ }^{1}$
}

\begin{abstract}
The abstract should In the era of the fourth industrial revolution today, the interaction between countries and cultures are no longer confined to overt geographical barriers due to technological advancement. However, these advances have created a countervailing effect on cultural identity, with a tendency to its loss; as well as cultural hegemony of one culture upon another culture. This phenomenon could be seen as well among foreign language learners. This critical literature study aims to examine the urgency of intercultural communication competence in foreign language learning to secure national cultural identity. This study has been commenced with the analysis of the development of intercultural interaction; determinant factors in intercultural competency integration of a language learning process; as well as the utilization of technology to enhance intercultural communication competency in the foreign language learning process. The result shows that information \& communication technology (ICT) is beneficial in the materials development for foreign language learning. It carries the role of a media in learning, also as a means of communication to integrate intercultural communication competency into the foreign language learning process in today's era of the Fourth Industrial Revolution.
\end{abstract}

Keywords: intercultural communication, foreign language, learning information, communication technology

\section{Introduction}

Technological progress together with industrial development has also been driving the interaction between nations and cross-cultural communication to be more communicative. Previously, geographical borders, resulting in time difference and distance has placed a significant communication barrier for geographically dispersed people or society. However, in the era of the industrial revolution as of today, technology advancement has helped people from diverse countries and cultural backgrounds to be easily connected. This also applies to the foreign language learning process. The internet and social media, either as a learning media or as a medium of interaction with native speakers, provide the opportunity for learners to access a wide range of information[1], [2].

However, these advances in cross-culture and cross-borders communication may also portray the emerging of cultural identity crisis and linguistic hegemony. This also implies foreign language learning where Western countries or second language-targeted countries (L2) 
tend to be the central focus to be studied; understood or well-respected, while the foreign language learner's own indigenous language \& culture are being neglected and abandoned. Hence, their indigenous language and/or cultures eventually become under-recognized, particularly for the young generation [3]-[5].

In Indonesia, the popularity of other countries' popular culture admired by many young people has become a core motivation to pick up a foreign language. On the other hand, our cultural products become alienated. Byram claims that one of the key factors of this phenomenon is because of the foreign language curriculum tend to be designed to serve instrumental purposes, such as the needs of abroad tourism/overseas travels' purposes, that implies to the neglection of awareness cultivation on own self country's identity [6].

In Western countries, many young people have an interest in cultures theme but perceive it as mere knowledge. A study in a variety of possibly interesting themes for a young generation has been conducted on secondary level students in the U.S. to be used as an input to the 21 st-century foreign language teaching standard. One of the themes that are being highlighted by many students was "culture". Unfortunately, they still perceive the needs of foreign language learning restricted as a piece of knowledge, and not to its applicability though they do aware that there is a strong connection between cultural knowledge and the use of language on a certain occasion. These students criticized the unavailability of a single culture standard for language teaching classrooms [7].

Therefore, it is essential to examine the attempts to integrating cultural dimensions to foreign language learning that would enable the learner to develop and nurture their understanding, curiosity level, expertise as well as awareness on their own culture whilst appreciating other countries' cultures through this learning process. Thus, departing from such concern, the aims of this literature study are: (1) to analyse the development of the understanding of the cross-culture and cross-border interaction concept; (2) to identify the type of cultural dimension which should have/best to be imbedded and nurtured through foreign language learning process; (3) to identify what are the attempts were taken to accomplish aim number 2 as well as the challenges; and (4) to study the role of technology in building intercultural communication competence in the foreign language learning process.

\section{Method}

This research utilizes three databases to capture published articles: ProQuest, Google Scholar, Google Books. The search will be constructed upon these keywords: "intercultural", "intercultural communication competence", "education in the era of fourth industrial revolution" or "education in the era of industry 4.0", and "information \& technology in language learning. These words are used due to its relevancy to the research topic: "intercultural competence integration in language learning in the era of the Fourth Industrial Revolution (Industry 4.0).

There is three (3) main analysis carried out by this study. The first analysis is the analysis of the development of the intercultural interaction concept. This analysis aims to explore the historical background of the term "intercultural". The second analysis is the analysis of intercultural communication competence and its connection with language learning. This analysis is performed to probe the indicators of intercultural values integration into language learning. The concluding analysis is the analysis of the utilization of Information \& Communication Technology (ICT). The third analysis is completed due to the consideration 
that there are changes in communication pattern and technology has held an important role as the result of the Fourth Industrial Revolution (Industry 4.0).

This research uses a data triangulation method to measure its reliability. This is conducted by comparing several expert's opinions upon the mentioned subtopics. The database search screening showed about 30 result articles that are relevant to the research topic: intercultural communication competence. Nevertheless, after examined and weight-based the result articles to its relevancy to "the use of technology in language learning ", only 19 articles are selected for inclusion. These 19 studies are used as the main references in providing a comparison of experts' viewpoints to analyze intercultural communication competence integration in language learning in the era of the Fourth Industrial Revolution.

\section{Results and discussions}

Culture can be defined as knowledge, custom, and language of a group of people, that are formed and passed down from generation to generation [8]. Hence, it emerges the awareness of the importance of teachers to teach their students to be able to understand and respect other cultures to enabling them to interact ineffective and with convenience in the wider society. With the awareness of the importance to respect other cultures, a term in the intercultural interaction \& communication field has been established in the era of the 1980s, that called "cross-cultural understanding". This term: "cross-cultural understanding" is recognized as communication and information exchange between two or more different cultures that enable them to reach a mutual understanding of cultures and the world where they live [8]).

In cross-cultural understanding education, students will acquire different culturalassociated bits of knowledge and skills as well as adsorbing new attitudes and values. Nevertheless, such "understanding "has been criticized by researchers, teachers and communication practitioners as its mainly orientated towards the culture of specifically targeted learning language but not taking into account our own country's culture. It has resulted in the tendency of the young generation to understand and master other culture easily, but no attention given to own self-culture. Therefore, in the 1990s, Byram has coined a new term in the field of intercultural interaction in a multicultural society to anticipate such weaknesses and critics against the concept of "cross-cultural understanding", well-known as intercultural communication [3], [9]-[11]. Byram, a Professor Emeritus in the School of Education who is attempting ways to incorporate culture into language teaching. Byram then further developed this concept as part of the Model of Intercultural Competence that wellknown as critical cultural awareness or savoir s'engager'. In his research development on intercultural competence in language education \& teaching.

Moreover, Byram also introduces the term "Intercultural Speakers". Intercultural speakers here is defined as someone with the ability not only to be able to understand the cultural dimension behind a foreign language but also able in comparing and discovering differences as well as similarities with their own culture of indigenous language [9]. The analysis of the culture of which is emphasized by Byram is a cultural analysis that provides both in the cognitive and the affective knowledge on cultures others and our own that relates to the language teaching discipline and frameworks. Up to recent times, the discourse on integrating intercultural communication competence into foreign language education is still ongoing together with its complexity of progress and existing challenges. Byram listed four (4) components of competencies in cross-culture communication required to be an intercultural communication speaker as follows: knowledge; skills; attitudes; and individual identity values. The explanation of each component will be provided below. 
The knowledge component as showed in the figure above refers to the knowledge of social groups; its interactions process; and the output from the interaction process within those social groups. This knowledge here includes how the social group itself views and accept the presence of the speakers. Then, the skills component required to be an Intercultural Speaker refers to the capability in interpreting; comparing; discovering as well as interacting with social groups from different cultures. Through mastering these abilities, it is expected that the intercultural speakers are better to understand the similarities and differences between their own culture and native speakers' culture; also, able to esteem both cultural identity and values.

The third component in the Model of ICC is attitudes. The attitudes expected for an Intercultural are a high level of curiosity and openness towards other cultures, complemented by the values a person holds; beliefs; and certain behaviors that may differ from the speaker's behavior. The last component in the model of Intercultural Communication Competence that is essential for an Intercultural Speaker to have is individual identity values. The concept of this identity refers to a sense of awareness of the existence of our nation and culture, then followed by a critical awareness of the native speaker's nation and culture. The model of Intercultural Communication Competencies (ICC) from Byram is illustrated in Figure 1 below [10].

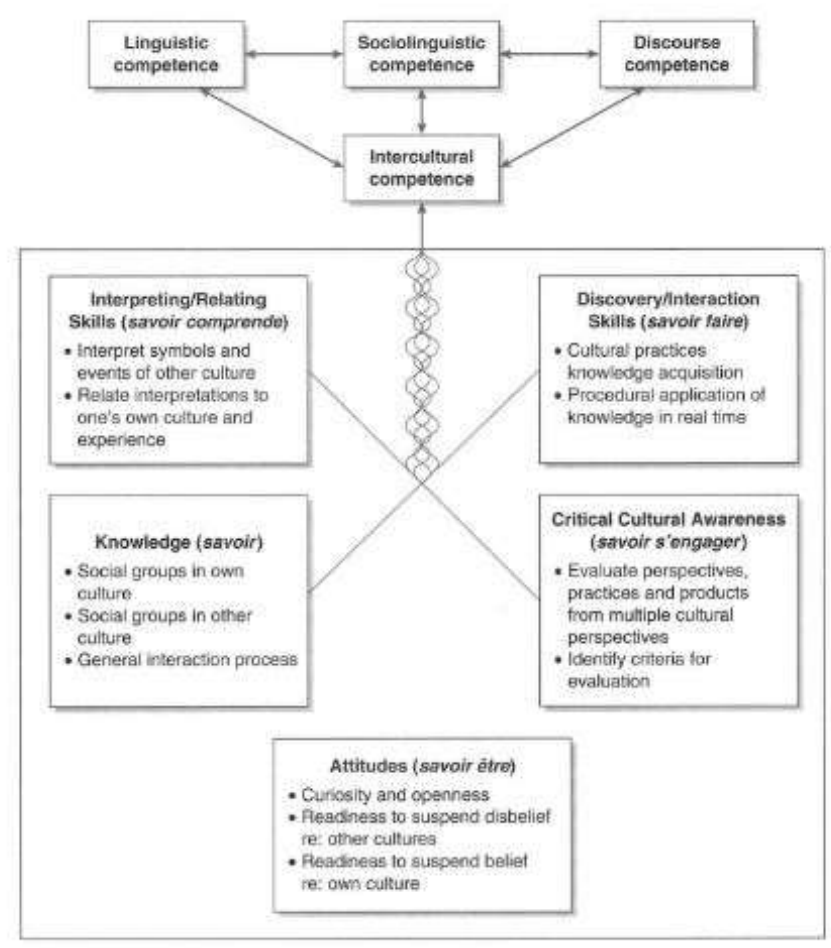

Fig.1. Byram's Model of Intercultural Communication Competence

It is highly expected that this will leads to a mutual appreciation toward diverse individual identities regarding different geographical backgrounds. To attain such "interaction" and "experience", Liddicoat suggests utilizing the technology enhancements in resolving the issue 
of distance and time. In this context, technology could be utilized as a medium to deliver "interaction" and "experience of intercultural communication" through a variety of means such as e-mail; chat applications; personal blog/blog services; video-based communication lines, etc [12].

The first factor that plays an important role in the progress of cultural dimension insertion into language learning to develop and nurture Intercultural Communication Competence is the language educator. In line with the research development on intercultural communication in language learning, there has been a growing number of efforts in preparing language educators with the capability to incorporate cultural dimension into language teaching. It is obligatory to teach and measure this Intercultural Communication Competency achievement in the teaching of English as a foreign language (EFL) in Hungary. However, many language educators incorporate the cultural dimension only as knowledge, meaning it only fulfills one component from a total of five (5) components. New Zealand provides a good example of such implementation[6].

There are massive cases where the application of Intercultural Communication Competence in language learning \& teaching already focuses on the third component: attitudes, and no longer limited to knowledge component and skills component. Unfortunately, most of the language teachers are focusing heavily on the culture of target country language but their own country culture receives little attention [13]. In this factor, language teacher plays a crucial role not only in the aspect of language teaching methodology but correspondingly to encourage learners in identifying personal self-identity linked to the critical cultural awareness component as mentioned in the model of Intercultural Communication Competence above [14].

The second determinant factor is the experience of intercultural interaction. Anthony J. Liddicoat reveals that ultimately there is a need to design a curriculum and teaching syllabus with assignments that allow the development of self-identity awareness as well as a mutual understanding among learners. Such design is essential in building the competency of a learner in Intercultural Communication. Liddicoat then further explained that the focus of inclassroom assignments needs to be centralized on interaction and experience. This indicates that the planned learning activities should provide a conducive setting for learners to build mutual interactions and share their experiences on the identification process of their selfidentity and communication partner [12].

The experience of studying abroad is one of the possible ways to offer an intercultural experience. Studying in the origin country would equip the person with a cultural experience, leading to an intercultural communication competence enhancement particularly on curiosity level as part of the Attitudes component of Byram' Model of Intercultural Communication Competence [15]. However, the opportunity to study overseas also deals with some constraints i.e. financial; political; etc. The third determinant factor that has been discoursed in the integration of the cultural dimension in the teaching of language is assessment and evaluation. There have been great efforts in establishing a standard for assessing intercultural competence in language teaching, include online-based self-evaluation through a smartphone application or official site.

Unfortunately, the standard in the assessment \& evaluation for Intercultural Communication Competence in school and higher education have only received a little attention [6]. The components of Intercultural Communication Competence should not primarily only gain knowledge but its application in the classroom learning process should be able to be measured by using the Intercultural Development/ ID Model which is formulated through the adoption of Byram' Intercultural Communication Competence concepts [16]. 
As previously mentioned in the final section of 3.2 that technology advances could be utilized to negate the issue of distance \& time in the efforts of providing intercultural experience for foreign language learners. Because not all learners have the privilege to study in foreign countries, researchers and foreign language teachers should identify the most beneficial way of leveraging technology for this matter. The rapid growth of technology has provided an opportunity for both learners and language educators to form an intercultural community through the online-based platform. This digital technology could be used through official websites or social media applications that feature two or multiple ways to interact (teacher-learner-teacher, between learners, between teachers) [1], [2], [17]-[20].

According to the Ministry of Communication and Information Technology of the Republic of Indonesia, there are about 63 million people as internet users in Indonesia and 95 percent of the total number of users are using the internet for a social network. The users have embraced social media in various activities such as blog writing; Instagram photos uploads; video upload on YouTube [21]. The research on the online exchange for intercultural learning shows that either the first generation of the web (Web 1.0) (e-mail, text-based message, discussion board) and second generation of the web (Web 2.0) (blog, podcast, etc.) could be used as an online medium for cultural exchange [20].

Web 1.0 refers to the first stage of the world wide web, system of cognition, read-only web and somewhat mono-directional. This first generation of web delivers information for users with a limited interaction ability for its users. The second generation is Web 2.0 which refers to blog; podcast; Web 2.0 is a web read-write which offers social interaction in the system [22]. With such an advantage, web 2.0 then allows the development of cross-cultural exchange among learners from diverse cultural backgrounds. Hence, facilitating them to obtain a multicultural perspective.

This telecollaborative interaction or also called as intercultural interaction offer various advantages such as follows: (1) as a means to practice communication in outside class environment; (2) improve self-confidence; (3) train to speak to calmly ; (4) to facilitate a feedback process either with fellows or performing self-evaluation; and (6) a means to increase creativity in learning a language [17], [18], [20]. Nevertheless, the utilization of technology upon intercultural networks also followed by several downsides. First, many pieces of research have highlighted the issue of confidentiality of learner's privacy upon some personal related themes such as family.

Furthermore, internet connection remains an issue in some countries, which have not been resolved yet. This implies that language educators should consider working with themes that provide greater privacy security for their learners. Other possible actions are to reduce the duration of the assignments; or divide the assignment into several parts to accommodate learners with internet connection difficulties to accomplish their tasks easier [1], [2], [19].

\section{Conclusion}

In this era of the fourth industrial revolution (Industry 4.0), communication is no longer restricted by either distance or time factor. With the great help of technology, global educators from many different parts across the globe are possible to perform communication though separated by thousands of miles apart as well as significant time difference. The existence of Information \& Communication made all matters easier. This also applies to foreign language learning. Some excuses such as the unavailability of a native speaker in the surrounding environment or the absence of experience living in the target language origin country (learning language' country). These excuses are categorized as those that could be resolved through the 
utilization of Information \& Communication Technology (ICT). Many types of research under applied linguistic field-a branch of language education- have proven that It could be used in the development of teaching materials, whether as a learning media or a means of communication in the language learning process.

On the other hand, the communication challenges in the Borderless Global Village are the cultural awareness issue, particularly the self-identity crisis, including those who are proficient in speaking international languages. There is a tendency that not only the issue of distance and time is diminishing, the indigenous cultural identity also seems to face serious regression, particularly in the young generation. Such a problem also arises in a foreign language learner' group. Many of them face difficulties and found themselves encounter awkward feelings to express their self-identity as well as in understanding the culture of their communication partner while conversing in a foreign language.

In the 1980s, many language educators have realized the importance of teaching their students to acknowledge, understand and appreciate other cultures. This will equip the learners to be able to interact effectively and conveniently in this global world. Such a realization was the departing point in inventing the concept of "cross-culture understanding". However, this concept received several critics from researchers, communication practitioner and teachers as it is considered to put a great focus on the culture of target language country but neglects our own culture. Then Byram introduces the concept of Intercultural Communication Competence. This concept comprises four components such as knowledge; skills; attitudes; and individual identity values. Moreover, this article has also examined the determinant factors in achieving Intercultural Communication Competence integration into foreign language learning \& teaching. The factors are language educator; intercultural interaction experience; and evaluation \& assessment of intercultural interaction process' achievement.

Lastly, the utilization of technology in intercultural networks or also called online intercultural exchange were also been discussed in this article. Various type of technology advances is beneficial to be used, either those that are designed to develop one-way interaction of communication ability or two and multi ways interaction. However, it is well noted that there should be a concern towards some emerging issues involving such technology enhancements such as privacy and internet access. It implies to the needs of educators/teachers to consider some possible actions: prepare themes that are lower risk to privacy disclosure; reduce the assignment duration, or divide the tasks into smaller parts to accommodate learners with a limited internet connection to complete the assignments easily.

Acknowledgment. The author gratefully acknowledges the use of the services and facilities of the International Seminar Grant at the Universitas Al Azhar Indonesia, funded by LP2M UAI.

\section{References}

[1] S. Canto, K. Jauregi, dan H. van den Bergh, "Integrating cross-cultural interaction through video-communication and virtual worlds in foreign language teaching programs: is there an added value?," ReCALL, vol. 25, no. 1, pp. 105-121, 2013.

[2] R. Godwin-Jones, "Integrating intercultural competence into language learning through technology," Lang. Learn. Technol., vol. 17, no. 2, pp. 1-11, 2013.

[3] M. Byram, P. Holmes, dan N. Savvides, "Intercultural communicative competence in foreign language education: Questions of theory, practice and research," Lang. Learn. $J .$, vol. 41, no. 3, pp. 251-253, 2013.

[4] A. Scardino, "Language assessment literacy as self-awareness: Understanding the role of 
interpretation in assessment and teacher learning," Lang. Test., vol. 30, no. 3, pp. 309327, 2013.

[5] I. Santoso, "Pembelajaran Bahasa Asing di Indonesia: Antara Globalisasi dan Hegemony," J. Pendidik. Bhs. dan Sastra, vol. 14, no. 1, pp. 1-11, 2014.

[6] M. Byram, "Twenty-five years on-from cultural studies to intercultural citizenship," Lang. Cult. Curric., vol. 27, no. 3, pp. 209-225, 2014.

[7] S. S. Magnan, D. Murphy, dan N. Sahakyan, "Standards through the perspectives of postsecondary students," Mod. Lang. J., vol. 98, no. S1, pp. 222-251, 2014.

[8] R. Shadiev dan Y. M. Huang, "Facilitating cross-cultural understanding with learning activities supported by speech-to-text recognition and computer-aided translation," Comput. Educ., vol. 98, pp. 130-141, 2016.

[9] M. Byram, "CHAPTER NINE COMPETENCE, INTERACTION AND ACTION: DEVELOPING INTERCULTURAL CITIZENSHIP EDUCATION IN THE LANGUAGE CLASSROOM AND BEYOND," in Intercultural communication competence: Conceptualization and its development in cultural contexts and interactions, Cambridge Scholars Publishing, 2014, pp. 190.

[10] M. Byram, B. Gribkova, dan H. Starkey, "Developing Intercultural Dimension in Language Teaching," A Pract. Introd. Teach. Strasburg. Counc. Eur., 2002.

[11] M. Byram, A. Nichols, dan D. Stevens, Developing intercultural competence in practice, vol. 1. Multilingual Matters, 2001.

[12] A. J. Liddicoat dan A. Scardino, Intercultural language teaching, and learning. John Wiley \& Sons, 2013.

[13] M. Fernández-Agüero dan C. Chancay-Cedeño, "Interculturality in the Language Class-Teachers' Intercultural Practices in Ecuador," RELC J., pp. 1-15, 2018.

[14] M. S. McEown, K. A. Noels, dan K. D. Saumure, "Students' self-determined and integrative orientations and teachers' motivational support in a Japanese as a foreign language context," System, vol. 45, no. 1, pp. 227-241, 2014.

[15] S. A. Houghton, "Exploring manifestations of curiosity in study abroad as part of intercultural communicative competence," System, vol. 42, pp. 368-382, 2014.

[16] S. A. Houghton, "Making intercultural communicative competence and identitydevelopment visible for assessment purposes in foreign language education," Lang. Learn. J., vol. 41, no. 3, pp. 311-325, 2013.

[17] M. Porto, "Intercultural citizenship education in an EFL online project in Argentina," Lang. Intercult. Commun., vol. 14, no. 2, pp. 245-261, 2014.

[18] R. O'Dowd, "The competences of the telecollaborative teacher," Lang. Learn. J., vol. 43, no. 2, pp. 194-207, 2015.

[19] E. Toyoda, "Intercultural knowledge, awareness, and skills observed in a foreign language classroom," Intercult. Educ., vol. 27, no. 6, pp. 505-516, 2016.

[20] L. Lee dan A. Markey, "A study of learners' perceptions of online intercultural exchange through Web 2.0 technologies," ReCALL, vol. 26, no. 3, pp. 281-297, 2014.

[21] Kominfo, "Kominfo : Pengguna Internet di Indonesia 63 Juta Orang," Jakarta, 07-Nov2013.

[22] S. Aghaei, M. A. Nematbakhsh, dan H. K. Farsani, "Evolution of the world wide web: From WEB 1.0 TO WEB 4.0," Int. J. Web Semant. Technol., vol. 3, no. 1, pp. 1, 2012. 